\title{
A 15 mV Inductorless Start-up Converter Using a Piezoelectric Transformer for Energy Harvesting Applications
}

\author{
Thomas Martinez, Gaël Pillonnet, Member IEEE, François Costa, Member IEEE
}

\begin{abstract}
This paper presents an inductor-less start-up converter for a sub-100 mV energy harvester based on an Armstrong oscillator topology using a piezoelectric transformer and a normally-on MOSFET. Two models of the converter have been detailed and validated experimentally for the start-up phase and steady-state operation to respectively determine the minimum start-up input voltage and the voltage gain. The models have been validated experimentally in a set-up associating the converter and a thermo-electric generator. Based on a Rosentype piezoelectric transformer and off-the-shelf components, the proposed start-up topology begins to oscillate at $15 \mathrm{mV}$ and achieves a $1 \mathrm{~V}$ output voltage at only $43 \mathrm{mV}$. Compared to the literature, the topology needs no inductive component and achieves self-starting operation with a smaller input voltage.
\end{abstract}

Index Terms-start-up converter, Armstrong oscillator, piezoelectric transformer, energy harvesting, cold-start

\section{INTRODUCTION}

THE progress in the scaling of micro-electronic devices and the reduction of their energy consumption have contributed to the development of low-power portable systems. For wireless sensor nodes or implantable device applications, batteries are unsuitable as they have a limited lifetime and may need maintenance and to be replaced [1]. For these low power applications, it is more interesting to be supplied by a completely autonomous system by harvesting the ambient energy. This makes it possible to develop "deploy and forget" sensor nodes that will not need any maintenance or replacement after they are installed and can work for several years. Several energy sources can be harvested such as light, heat, mechanical vibrations, electromagnetic radiations and chemical energy from bacteria reactions [2]. Among those possibilities, thermo-electric generators (TEG) and rectennas [3] provide DC voltages from thermal and electromagnetic energy harvesting, respectively. In most applications, the TEG provides ultra-low voltage $(<100 \mathrm{mV})$ but has a low internal resistance $(<10 \Omega)$ while the rectenna has an internal resistance in the range of $100 \Omega$ to a couple of $\mathrm{k} \Omega$ [3]. However, they both constitute interesting solutions for

T. Martinez is with the laboratory SATIE (Systems \& Applications of Information \& Energy Technologies), ENS Cachan, 91120 Cachan, France.

G. Pillonnet is with the University of Grenoble Alpes, Grenoble 38000, France, and also with the CEA, Leti-MINATEC Campus, Grenoble 38054,France (e-mail: gael.pillonnet@ cea.fr).

F. Costa is with the University Paris-Est-Créteil (UPEC), Créteil 94000, France and also with the laboratory SATIE (Systems \& Applications of Information \& Energy Technologies), ENS Cachan, 91120 Cachan, France applications which consume less than a few hundred microwatts.

The voltages provided by energy harvesters strongly depend on the ambient conditions and they must be adapted in order to supply the load. An interface circuit is needed to step-up the voltage, track the maximal power, store the energy and supply the node sensor at maximum efficiency. Classical switchedmode DC-DC converters already achieve these functions [4] [5].

An additional specific constraint inherent to energy harvesting is the "cold start", i.e. to start the circuit when the storage element is fully discharged. When the voltage supplied by the harvester is lower than the threshold voltage of the transistors used in the switched-mode converter, the system cannot start and step-up the harvester output voltage. Many papers avoid this issue by assuming an initial energy is provided to the circuit by the storage element [6] but this is not suitable for applications after long standby periods.

The architecture of the proposed solution is presented in Fig. 1. A start-up converter is added to the circuit which acts as an intermittent supply. In fact, it must start at the voltage provided by the harvester when the battery is discharged, stepup the harvester output voltage and initially charge a storage capacitor. The main constraint of the start-up converter is to start at the voltage provided by the harvester which may be lower than $100 \mathrm{mV}$ and to step-up the output voltage high enough in order to supply the drive of the main DC-DC converter. Its power efficiency is therefore not the most important parameter. When $\mathrm{C}_{\text {start }}$ has reached a sufficient voltage, the energy stored will then supply the optimized main converter whose main focus is efficiency.

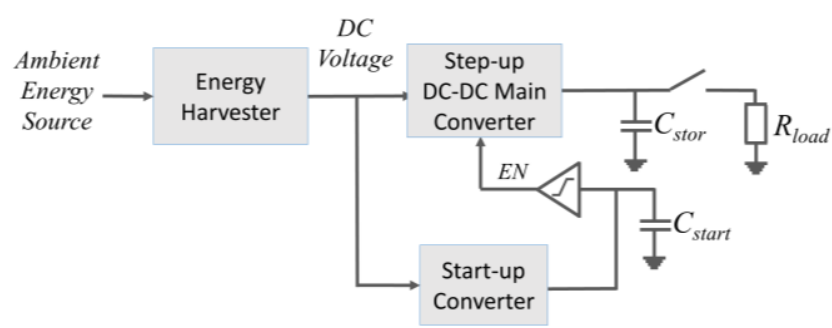

Fig. 1: Overall architecture of the conversion circuit

Several low start-up voltage converters have been proposed. Some systems use classical switched mode architectures while focusing on lowering the threshold-voltage of the transistors whereas other fabrication process with low threshold voltage 
transistors [7] can be used or forward body-biasing [8]. The use of a charge pump with depletion-mode transistors has also been proposed [9]. Here, these converters are still limited by the threshold voltage of the transistors but has difficulty starting at voltages lower than $100 \mathrm{mV}$. Reference [10] proposes a boost converter activated by a mechanical switch that starts at $35 \mathrm{mV}$ but this needs an external vibration that is not always available. Other low voltage start-up converters consist of resonant step-up oscillators such as the Armstrong Oscillator architecture based on a magnetic transformer and an amplifying element [11]. In [12], the converter uses this architecture to start from a TEG source at voltages as low as $40 \mathrm{mV}$. In [13],the Armstrong oscillator is also used to start from an RF source from a $100 \mathrm{mV}$ input voltage. Several transformers can be cascaded to achieve a start-up voltage as low as $6 \mathrm{mV}$ [14]. All those propositions have the inconvenience of being implemented with magnetic transformers. In [15] and [16], ultra-low voltage resonant oscillators are combined with a charge pump converter to start at voltages as low as $10 \mathrm{mV}$ and $100 \mathrm{mV}$, respectively, but they also use a bulky inductance to realize the conversion. Furthermore, most of these solutions are only compatible with harvesters with a low internal resistance such as a TEG $(<10$ $\Omega)$.

The use of resonant oscillators enables a low start-up voltage to be obtained but the magnetic transformers and inductors are bulky elements that increase the size of the converter and are difficult to shrink and integrate with microelectronic techniques. However, piezoelectric transformers (PT's) constitute an interesting alternative to magnetic ones. They are notably used as power converters for cold cathode fluorescent lamps used in liquid crystal displays (LCD's) [17]. They may exhibit higher voltage gain and power density than magnetic transformers and a quality factor as high as 1000 [18]. Furthermore, their use in power converters allows the electromagnetic radiation of the system to be limited [19]. The relative high Curie temperature $\left(>200^{\circ} \mathrm{C}\right)$ of certain ceramic elements may also allow PT's to work at higher temperatures than a magnetic element [20]. Their integration on silicon has already been realized and their compatibility with classical microelectronic fabrication processes demonstrated [21]. Reference [22] presents a start-up converter based on a resonant oscillator using a PT with start-up voltages of $69 \mathrm{mV}$ for an inductor-less circuit but it is only suitable for low internal resistance harvesters, or coupled to an inductor [23].

In this paper, a self-start-up converter based on an Armstrong oscillator using a PT and a "biasing element", i.e. a resistor, replacing the magnetic transformer is presented. The objective is that the circuit self-starts using the voltage provided by the harvester whether it is a TEG, rectenna or biofuel cell, and to step it up at to a voltage sufficiently high to start the main converter. The proposed circuit is completely inductorless, does not generate any electromagnetic interference and could work at high temperatures and have the potential to be integrated more easily in a microelectronic process flow. The circuit has been modeled in both start-up phase and steady state which has allowed the start-up voltage and output voltage of the converter to be determined, respectively. These models were then validated through a time-domain simulation. The converter has been fabricated on a printed circuit board (PCB) in order to validate the simulation results. This paper describes the electrical characteristics of the PT and the behavior of the converter in section II. The models of the circuit are then described in section III. Then, the experimental realization and measurements are presented in section IV. Finally, we compare the results obtained with the analytical models, the simulation and experimental measurements before discussing the performances and the design trade-off of this novel startup converter.

\section{START-UP CONVERTER TOPOLOGY BASED ON PIEZOELECTRIC TRANSFORMER}

\section{A. Piezoelectric Transformer}

Firstly, we will describe the behavior and electrical characteristics of the PT which is the basis of the proposed converter. The working principle of a PT is well known and presented in [21]. An electrical equivalent circuit of the PT can be extracted based on the analogy between the equations of an RLC series electrical circuit and the dynamic vibration of a mechanical structure [24]. The force applied on an element in the structure corresponds to a voltage and the velocity of the wave is represented by a current. Without an external load at the output, this leads to the circuit presented in Fig. 2 (a) for a three electrodes transformer where the primary and secondary sides have a common electrode. The RLC series circuits in parallel correspond to a mechanical vibration at the fundamental and harmonic frequencies. The ideal transformers represent the piezoelectric effect and the input and output capacitances are those of the electrodes. A PT is designed to work at a specific frequency and the previous circuit can be simplified when it operates close to the resonant frequency by the circuit presented in Fig. 2 (b).

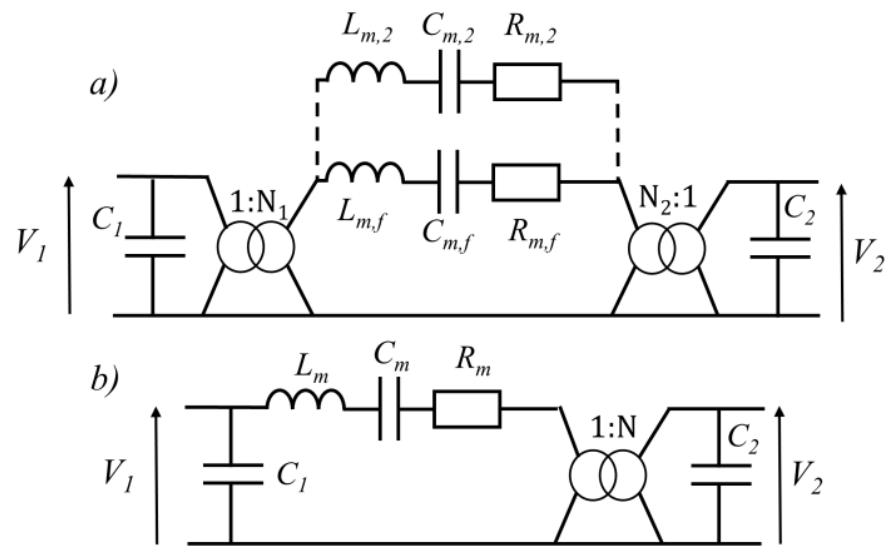

Fig. 2 (a) Equivalent circuit of a PT

(b) Simplified equivalent circuit of a PT for a specific resonant frequency

The PT commonly used in step-up applications is the Rosen type. It exhibits a high voltage gain that depends on the length to thickness ratio and a smaller output capacitance compared to other PT architectures [21]. To increase the voltage gain and the input capacitance, a multilayer topology is selected [25]. For our experiments, the off-the-shelf PT chosen is a Rosen-type multilayer one whose dimensions are $30 \times 1 \times 5$ $\mathrm{mm}$ [26]. Its equivalent parameters are presented in Table I.

From the equivalent circuit, the impedance of the unloaded 
PT seen from the input is equal to:

$$
Z_{P T, 1}=\frac{R_{m}+j\left(L_{m} \omega-\frac{1}{C_{e q} \omega}\right)}{1+j C_{1} \omega\left(R_{m}+j\left(L_{m} \omega-\frac{1}{C_{e q} \omega}\right)\right)}
$$

where $C_{e q}=\frac{C_{m} \cdot N^{2} \cdot C_{2}}{C_{m}+N^{2} \cdot C_{2}}$ is the equivalent capacitance when the output capacitance $\mathrm{C}_{2}$ is reported back in the RLC series circuit.

The main parameters of our PT are given in Table. I. The impedance curve measured at the input of the unloaded PT shows two resonances. The first and second ones corresponds to the series and parallel resonant frequency respectively and can be expressed as:

$$
f_{s}=\frac{1}{2 \pi \sqrt{L_{m} C_{e q}}}, \quad f_{p}=\frac{1}{2 \pi \sqrt{L_{m} C_{e q, i n}}}
$$

where $C_{e q, i n}=\frac{C_{e q} \cdot C_{1}}{C_{e q}+C_{1}}$.

In our start-up converter, a capacitive load $\mathrm{C}_{\text {load }}$ is structurally added at the output of the PT in parallel with $\mathrm{C}_{2}$ (see later in Fig. 4). This capacitance $\mathrm{C}_{\text {load }}$ is due to the internal capacitance of the elements at the output of the PT in our topology (diode, transistors). The output capacitance is then $\mathrm{C}_{\text {out }}=\mathrm{C}_{2}+\mathrm{C}_{\text {load }}$ and the $\mathrm{C}_{\mathrm{eq}}$ value changes with $\mathrm{C}_{\text {out }}$ replacing $\mathrm{C}_{2}$. The resonant frequencies are then switched to lower ones. The capacitive load $\mathrm{C}_{\text {load }}$ also has an impact on the voltage gain of the PT. The voltage gain $V_{2} / V_{1}$ is given by:

$$
G_{P T}=\frac{V_{2}}{V_{1}}=\frac{1}{N j C_{\text {out }} \omega\left(R_{m}+j\left(L_{m} \omega-\frac{1}{C_{e q} \omega}\right)\right)}
$$

Fig. 3 represents the voltage gain of the PT as a function of the frequency for different capacitive loads. The gain reaches a maximum at the series resonant frequency $f_{s}$ of the PT. For a high output capacitance, this frequency coincides with the mechanical resonance defined by the geometric parameters. When the output capacitance decreases, the resonance frequency $f_{s}$ is shifted away from this mechanical resonance to higher frequencies. On the other hand, the voltage gain increases as the output capacitance decreases demonstrating the importance of the limitation of the load capacitance in order to obtain a high voltage gain when designing the circuit.

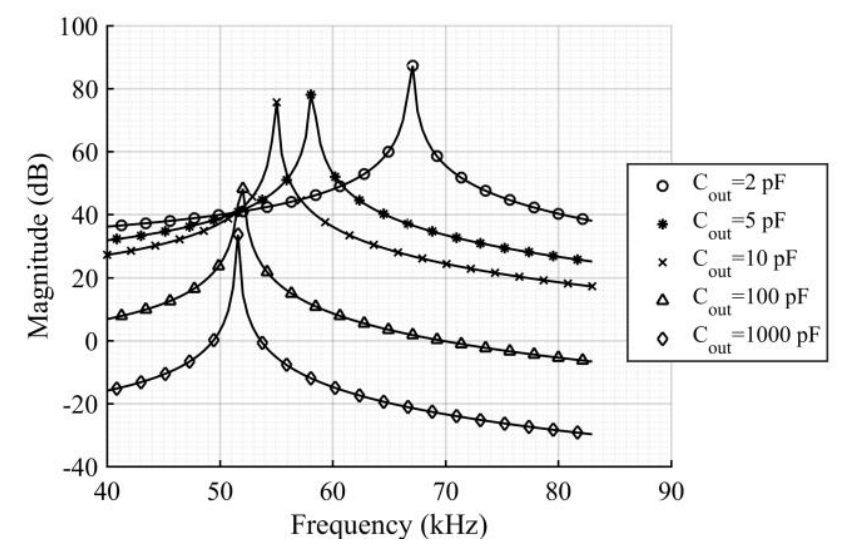

Fig. 3: Voltage gain of the PT vs. output capacitance $\mathrm{C}_{\text {out }}$

\begin{tabular}{|c|c|}
\hline Parameters & Value \\
\hline \multicolumn{2}{|c|}{ Piezoelectric Transformer SMMTF53P3S45 } \\
\hline $\mathrm{C}_{1}$ & $90 \mathrm{nF}$ \\
\hline $\mathrm{C}_{2}$ & $11.5 \mathrm{pF}$ \\
\hline $\mathrm{R}_{\mathrm{m}}$ & $1.4 \Omega$ \\
\hline $\mathrm{L}_{\mathrm{m}}$ & $2 \mathrm{mH}$ \\
\hline $\mathrm{C}_{\mathrm{m}}$ & $4.77 \mathrm{nF}$ \\
\hline $\mathrm{Q}_{\mathrm{m}}$ & 462 \\
\hline $\mathrm{N}$ & 58,8 \\
\hline \multicolumn{2}{|c|}{ Transistor ALD210800 } \\
\hline $\mathrm{V}_{\text {th }}$ & $-37 \mathrm{mV}$ \\
\hline$\beta=\mu_{0} \cdot \mathrm{C}_{\mathrm{ox}} \cdot \mathrm{W} / \mathrm{L}$ & $11.2 \times 10^{-3} \mathrm{~A} / \mathrm{V}^{2}$ \\
\hline $\mathrm{C}_{\mathrm{g}, \mathrm{in}}$ & $4.7 \mathrm{pF}$ \\
\hline \multicolumn{2}{|c|}{ Diode 1PS66SB17 } \\
\hline $\mathrm{C}_{\text {diode }}$ & $0.8 \mathrm{pF}$ \\
\hline Forward Voltage $\mathrm{V}_{\mathrm{F}}$ at $\mathrm{I}_{\mathrm{F}}=0.1 \mathrm{~mA}$ & $0.3 \mathrm{~V}$ \\
\hline \multicolumn{2}{|c|}{$\begin{array}{ll}\text { Miscellaneous } \\
\end{array}$} \\
\hline Harvester internal resistance $\mathrm{R}_{\mathrm{t}}$ & $2.8 \Omega$ \\
\hline $\mathrm{R}_{\mathrm{f}}$ & $20 \mathrm{M} \Omega$ \\
\hline $\mathrm{C}_{\text {start }}$ & $1 \mathrm{nF}$ \\
\hline
\end{tabular}

TABLE I

CIRCUIT PARAMETERS

\section{B. Converter topology}

The proposed start-up converter is presented in Fig. 4. Firstly, the energy harvester is represented by an ideal voltage source with a resistance in series representing its internal impedance. The second part is the classical Armstrong resonator with the $\mathrm{PT}$ as a replacement of the magnetic transformer. In the schematic, the ideal transformer ratio is set to $-\mathrm{N}$ as in a real converter the electrodes at the output are inverted. The active component was chosen as a normally-on depletion-mode MOSFET [27]. The Armstrong Oscillator works as a classical resonant oscillator. The PT acts as a feedback loop that filters one specific resonance frequency. The normally-on transistor acts as a transconductance which increases the current in the primary side of the PT when the gate voltage increases. The amplification allows the losses in the feedback loop to be compensated for and to increase the amplitude of the oscillating signal.

Compared to the classical Armstrong oscillator, a biasing resistor $\mathrm{R}_{\mathrm{in}}$ is added in parallel to the input capacitance of the transformer to set the DC point of the drain-source voltage. Contrary to a magnetic transformer, the two primary side branches of a PT have a capacitive part that prevents any DC current from flowing in the FET. The transistor subsequently has no clearly defined biasing point thus no oscillation is guaranteed. The resistor in parallel to the PT enables a current to flow in the FET at the beginning of operation, solving the polarization problem. A single diode rectifier forms the output stage. The chosen diode is a Schottky to reduce the capactive PT load and obtain the higher output voltage. This stage converts the oscillating signal into a DC voltage and charges the storage capacitance $C_{\text {start }}$. The resistance $R_{\text {start }}$ represents the insulation resistance of $C_{\text {start }}$ A resistor $R_{f}$ is also added between the gate of the transistor and the ground in order to set the DC polarization of the gate. This resistor may have a significant influence on the voltage gain and has large value in order to neglect its impact in the following. In the proposed circuit, the resistor value $R_{\mathrm{f}}$ is $100 \mathrm{M} \Omega$. 


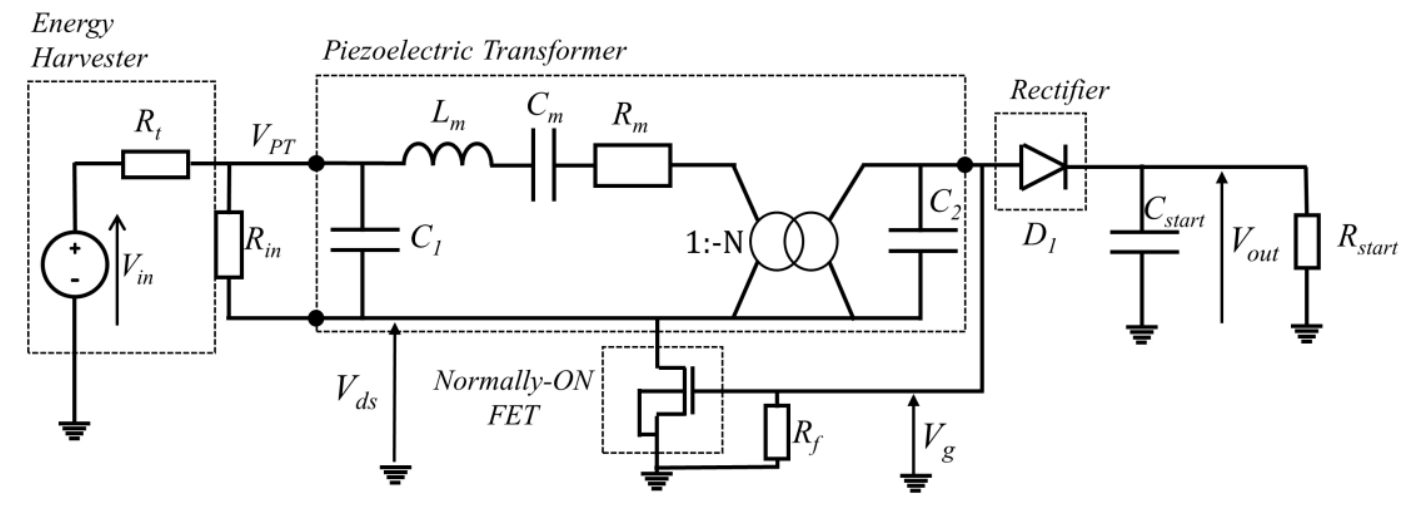

Fig. 4: Circuit Schematic

If the transistor operates in the linear region, the inherent noise in the gate signal is amplified and then transmitted through the selective filter constituted by the PT. Consequently, a positive feedback loop is created. Under specific conditions that will be explained hereunder, an AC current at a specific frequency appears in the primary side that translates into an amplified AC voltage at the output of the piezoelectric transformer. As soon as the amplitude of this signal reaches the threshold voltage of the Schottky diode, the storage capacitance starts to charge quickly. Due to the losses and the non-linearity in the transistor, the converter reaches a steady state, which gives the maximum output voltage available.

\section{MODELING OF THE CONVERTER}

The two main parameters in the design of a start-up converter are the start-up voltage and the voltage gain in steady state. The first parameter determines at which input voltage the oscillation can start; the latter determines the voltage that will supply the optimized converter and must be maximized. Most papers only tackle the start-up phase to determine the start-up voltage and oscillation frequency. In this paper, the modeling is separated in two parts to overcome the two design constraints: the start-up phase analysis determines the voltage at which oscillation begins whereas the analysis of the circuit in steady state gives information on the output voltage. In the following analysis, the PT is considered as a four-electrode device compared to the three-electrode one presented in Fig. 2 and Fig. 4. The secondary electrode connected to the drain of the transistor in Fig. 4 is considered as connected to the ground in Fig. 5 to simplify the analysis as we considered the feedback voltage $\mathrm{V}_{\mathrm{g}}=\mathrm{V}_{\mathrm{ds}}+\mathrm{V}_{\mathrm{C} 2}$ applied to the FET gate governed mainly by $\mathrm{V}_{\mathrm{C} 2}$ and not by the signal $\mathrm{V}_{\mathrm{ds}}$ as $\mathrm{V}_{\mathrm{C} 2}>>\mathrm{V}_{\mathrm{ds}}$ due to the inherent high voltage gain of the PT.

\section{A. Start-up phase modeling}

The oscillation condition can be determined based on a small-signal analysis and by applying the Barkhausen criterion. The small-signal equivalent circuit is represented in Fig. 5. The objective of the analysis is to determine the openloop gain $\mathrm{G}_{\mathrm{OL}}$ of the converter by opening the loop at $\mathrm{V}_{\mathrm{g}}$ when the output of the PT and the gate of the MOSFET are disconnected. From this, the Barkhausen criterion states that oscillation starts if the following condition is fulfilled, $G_{O L}$ is the open-loop gain of the circuit:

$$
\left|G_{O L}\right|>1 \text { and } \arg \left(G_{O L}\right)=0[2 \pi]
$$

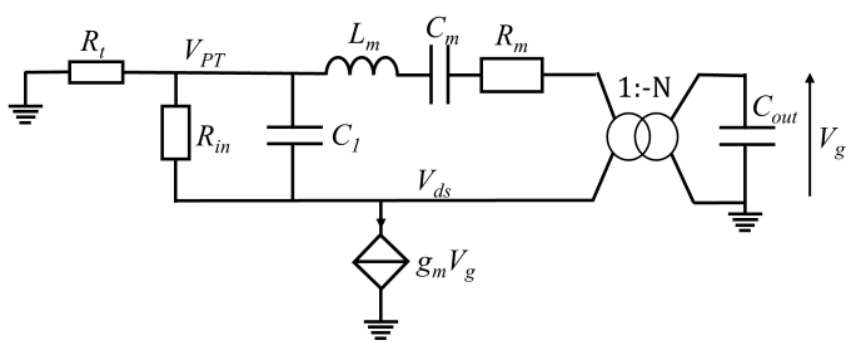

Fig. 5: Small-signal equivalent circuit

At the beginning of operation, if the output capacitances are discharged, we can assume that the DC voltage applied to the gate is equal to zero. The transistor is assumed to act as a transconductance. As the threshold voltage is close but inferior to zero, we can assume that the transistor works in strong inversion but its operation region (triode or saturation) depends on the drain-source DC voltage. The $\mathrm{DC}$ value of $\mathrm{V}_{\mathrm{ds}}$ that determines the operation region is defined by the input voltage, the resistances $R_{t}$ and $R_{i n}$ and the MOSFET $R_{o n}$ resistance. With $V_{g s}=0 V$, the resistance in saturation and linear region of a MOSFET is defined respectively as:

$$
\left\{\begin{array}{c}
R_{\text {on,sat }}=\frac{2 V_{d s}}{\beta V_{t h}^{2}} \text { if } V_{d s}>-V_{t h} \\
R_{\text {on,lin }}=-\frac{2}{\beta\left(V_{t h}+V_{d s}\right)} \text { if } V_{d s}<-V_{t h}
\end{array}\right.
$$

Where $\mathrm{V}_{\text {th }}$ is the threshold voltage, $\beta=\mu C_{o x} W / L ; \mu$ is the mobility of electrons in the semi-conductor, $\mathrm{C}_{\mathrm{ox}}$ is the gateoxide capacitance per unit area, $\mathrm{W}$ the width of the channel and $\mathrm{L}$ the length. $\mathrm{V}_{\mathrm{ds}} \mathrm{DC}$ voltage is then defined for the two modes

as $V_{d s}=\frac{R_{o n} \cdot V_{i n}}{R_{o n}+R_{t}+R_{\text {in }}}$, which results in an equation that can be solved for $\mathrm{V}_{\mathrm{ds}}$. This equation is solved numerically to extract the $\mathrm{V}_{\mathrm{ds}}$ value for the two operating regions from the parameters of the circuit (see Table I). From this resolution we 
can then precise the operating regions and the DC drain-source voltage. This result is critical as the transconductance value is defined differently in saturation and linear regions respectively, by:

$$
\left\{\begin{array}{c}
g_{m, s a t}=-\beta V_{t h} \\
g_{m, l i n}=\beta V_{d s}
\end{array}\right.
$$

In the following, we assume $g_{m}$ is the transconductance of the transistor that has been determined from the numerical resolution e.g. Matlab in our case prior to the small-signal analysis.

The open-loop gain of the oscillator is characterized by the transconductance of the transistor, the input impedance of the PT and its voltage gain. The current flowing through the FET is $i_{d s}=g_{m} V_{g}$. Thus, the voltage at the input of the PT is given by:

$$
V_{P T}-V_{d s}=g_{m} V_{g} Z_{i n}
$$

where $Z_{\text {in }}=\frac{Z_{P T} R_{\text {in }}}{Z_{P T}+R_{\text {in }}}$ and $Z_{P T}$ is defined as in (1).

Finally, the open-loop gain is:

$$
\begin{aligned}
G_{O L}=- & \frac{G_{P T}\left(V_{P T}-V_{d s}\right)}{V_{g}} \\
= & \frac{-g m}{N j \omega C_{\text {out }}\left(1+\left(\frac{1}{R_{\text {in }}}+j C_{1} \omega\right)\left(R_{m}+j\left(L_{m} \omega-\frac{1}{C_{\text {eq }} \omega}\right)\right)\right)}
\end{aligned}
$$

The value of $\mathrm{G}_{\mathrm{PT}}$ is given by (3). The opposite of $\mathrm{G}_{\mathrm{PT}}$ is taken here to take into account that in our circuit, the ideal transformer ratio is equal to $-\mathrm{N}$ to obtain a positive reaction of the loop. In practical terms, this only means an inversion of the electrodes at the output. This is necessary to fulfill the Barkhausen criterion and to have a phase shift of the openloop gain $\mathrm{G}_{\mathrm{OL}}$ of $0[2 \pi]$.

Fig. 6 represents the magnitude and phase of the input impedance $Z_{\text {in }}$, the PT voltage gain $-G_{\mathrm{PT}}$ and open-loop gain $\mathrm{G}_{\mathrm{OL}}$. The oscillation frequency of the circuit is determined at the frequency where the phase-shift of the open-loop gain is equal to $0[2 \pi]$ (Barkhausen criterion). We observe herein that this frequency is close to the parallel resonant frequency of the PT $f_{p}=55.8 \mathrm{kHz}$ for our circuit values. At this frequency, the input impedance phase is at $0^{\circ}$ as we are at a resonant point. The voltage gain is away from its resonance and the phase of the voltage gain is close, but not exactly equal, to $0^{\circ}$. The operation frequency is slightly displaced from the resonant parallel frequency to have the phase shift of the complete open-loop equal to $0^{\circ}$. For our PT and circuit, the value of the oscillation frequency is $f_{o s c}=55.81 \mathrm{kHz}$ and we can assume that $f_{o s c}=f_{p}$. A trade-off between maximizing $\left|Z_{\text {in }}\right|$ and $\left|\mathrm{G}_{\mathrm{PT}}\right|$, which influences input voltage and voltage PT gain, respectively, set this frequency.

The Barkhausen criterion gives the condition for the minimum input voltage in order to start oscillation. The input voltage of the harvester impacts the value of the transconductance of the transistor $\mathrm{g}_{\mathrm{m}}$ in the open-loop gain. The condition $\mathrm{G}_{\mathrm{OL}}>1$ then gives a minimum value for the minimum input voltage as a function of the biasing resistance. The minimum start-up parameters are extracted with Matlab. The results of the analysis will be discussed in section V.

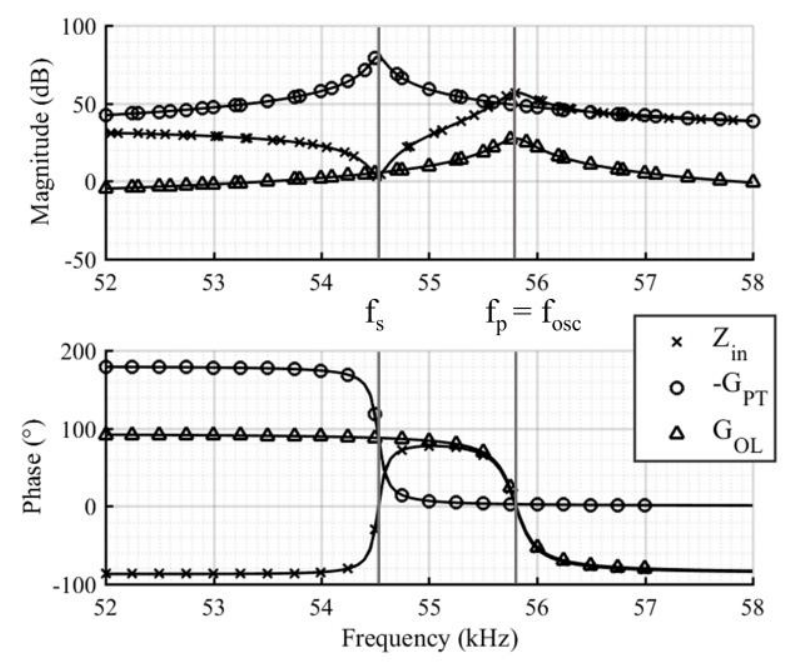

Fig. 6: Magnitude and phase of the input impedance, the PT voltage gain and the total open-loop gain.

\section{B. Steady-state modeling to predict voltage gain}

The previous analysis allows the oscillation conditions to be predicted, i.e. the minimum input voltage to apply and the oscillation frequency, but fails to determine the voltage gain of the converter in steady-state. The objective of the analysis in steady-state is to determine the amplitude of the oscillating signal and thus the output voltage of the start-up converter.

During steady-state, the previous small signal model is no longer valid as the oscillating signal $\mathrm{V}_{\mathrm{g}}$ may be lower than the threshold voltage $\mathrm{V}_{\text {th }}$ and thus the transistor in cut-off region. During one period, the transistor will go through all operation regions thus inducing non-linearity in the circuit. The solution to this problem is to realize a large-signal analysis. Our is derived from [28] for the Colpitts oscillator and is adapted here to the Armstrong oscillator. The gate voltage and output voltage in steady state are represented in Fig. 7.

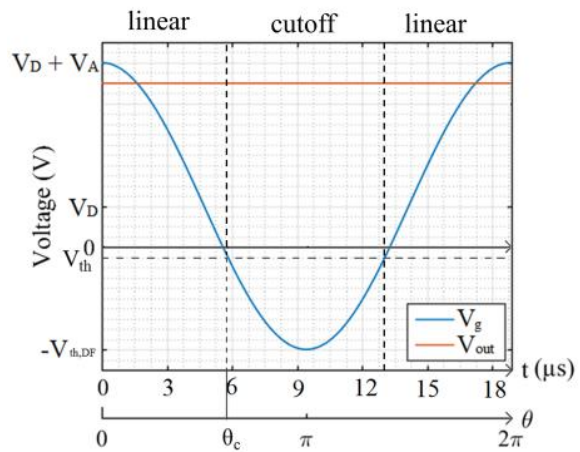

Fig. 7: Gate and output voltages in steady-state during a period of oscillation

Several assumptions are made during the analysis in order to have a tractable and representative analytical model of the output voltage. They are as follows:

1) The resonant oscillator only works at a specific frequency determined by the Barkhausen criterion and is dependent on the PT characteristics. The harmonic frequencies of the PT are neglected. We can then assume that the gate voltage is a pure sine wave at the parallel resonant frequency and has an amplitude $\mathrm{V}_{\mathrm{A}}$. The oscillation pulsation is then noted $\omega_{\text {osc }}$. 
2) The transistor has an internal protection diode $D_{F}$ between the gate and the ground as represented in Figure 8 , limiting the negative value of the gate voltage. This diode has a threshold voltage $\mathrm{V}_{\text {th,DF }}$ that limits the minimum voltage of $\mathrm{V}_{\mathrm{g}}$. The $\mathrm{DC}$ voltage of the gate is then not equal to 0 but has a positive value $V_{D}$ when the amplitude of the signal is higher than $\mathrm{V}_{\text {th,DF}}$.

3) The diode of the rectifier is not considered in the analysis, as it will induce non-linearity. We will only consider it by adding its junction capacitance to the load capacitance $\left(\mathrm{C}_{\text {diode }}\right.$ in Fig. 8).

4) We neglect the current flowing into $R_{f}$ and its impact on the gate voltage.

5) At the oscillation frequency, the RLC series circuit does not work at its resonance frequency but at a higher one. Away from the resonance, an RLC series circuit is assumed to have an inductive nature. It can then be represented by a simple LR circuit. The LC circuit formed by the input capacitance and the equivalent inductance has the same oscillation frequency as the global circuit and so $\mathrm{L}_{\mathrm{eq}}$ is equal to :

$$
L_{e q}=\frac{1}{\omega_{o s c}^{2} C_{1}}
$$

6) In steady-state, we can assume the gate voltage amplitude is large compared to the MOSFET threshold voltage and the drain-source voltage. The time during which the transistor is in saturation mode ( $\mathrm{Vg}>\mathrm{V}$ th and $\mathrm{Vg}<\mathrm{Vds})$ is small compared to the time spent in linear and cutoff regions. In the following part, the transistor is assumed to work only in the cutoff and linear regions (see Fig. 7).

The final equivalent circuit used during the large-signal analysis is presented in Fig. 8. From the previous assumptions we can define $\mathrm{V}_{\mathrm{g}}$ equals to:

$$
V_{g}=V_{D}+V_{A} \cos \left(\omega_{o s c} t\right)
$$

The value $\mathrm{V}_{\mathrm{D}}$ is the $\mathrm{DC}$ value of $\mathrm{V}_{\mathrm{g}}$ and depends on the transistor diode threshold voltage and amplitude of the signal as $V_{D}=-V_{t h, D F}+V_{A}$.

We can determine the current flowing in the RLC series branch from the following equation:

$$
i_{R L C}=-N i_{C_{\text {out }}}=N C_{\text {out }} V_{A} \omega_{\text {osc }} \sin \left(\omega_{\text {osc }} t\right)
$$

The sinusoidal voltage at the input of the PT is determined from the current equation. On the other hand, the simplification of the RLC series circuit does not take into account the voltage drop from the ideal transformer and the initial capacitance $C_{m}$. Therefore, we add the DC-value $V_{B}$ to the input voltage that will be determined later. Furthermore, the PT selects a specific frequency but at the input of the PT, due to the non-linearity of the transistor, harmonic frequencies play a role. The final value for the PT-input voltage is thus:

$$
\begin{array}{r}
V_{\text {in }, P T}=V_{P T}-V_{d s}=V_{B}+L_{e q} N C_{o u t} V_{A} \omega_{o s c}^{2} \cos \left(\omega_{o s c} t\right) \\
+N R_{m} C_{o u t} V_{A} \omega_{o s c} \sin \left(\omega_{o s c} t\right)+\sum_{k>1} V_{k} \cos \left(k \omega_{o s c} t\right)
\end{array}
$$

where $V_{k}$ are the amplitudes of the harmonic frequencies.

The current in the biasing resistor and capacitance are then determined as :

$$
\begin{aligned}
& i_{R_{\text {in }}}=\frac{V_{\text {in }, P T}}{R_{\text {in }}} \\
& =\frac{V_{B}}{R_{\text {in }}}+\frac{L_{e q}}{R_{\text {in }}} N C_{\text {out }} V_{A} \omega_{o s c}^{2} \cos \left(\omega_{o s c} t\right) \\
& +N \frac{R_{m}}{R_{\text {in }}} C_{\text {out }} V_{A} \omega_{\text {osc }} \sin \left(\omega_{\text {osc }} t\right)+\sum_{k>1} \frac{V_{k}}{R_{\text {in }}} \cos \left(k \omega_{\text {osc }} t\right) \\
& i_{C_{1}}=C_{1} \frac{d V_{i n, P T}}{d t} \\
& \begin{array}{r}
=-C_{1} L_{e q} C_{o u t} N V_{A} \omega_{o s c}^{3} \sin \left(\omega_{o s c} t\right) \\
+N R_{m} C_{o u t} C_{1} V_{A} \omega_{o s c}^{2} \cos \left(\omega_{o s c} t\right) \\
-\sum_{k>1} V_{k} C_{1} k \omega_{o s c} \cos \left(k \omega_{o s c} t\right)
\end{array}
\end{aligned}
$$

Finally, the current flowing in the transistor is equal to:

$$
i_{d s}=i_{C_{1}}+i_{R_{\text {in }}}+i_{R L C}
$$

From the current $i_{d s}$, the drain-source voltage $V_{d s}$ is determined as:

$$
V_{d s}=V_{P T}-V_{i n, P T}=V_{i n}-i_{d s} R_{t}-V_{i n, P T}
$$

where $\mathrm{V}_{\mathrm{in}, \mathrm{PT}}$ is defined by (12).

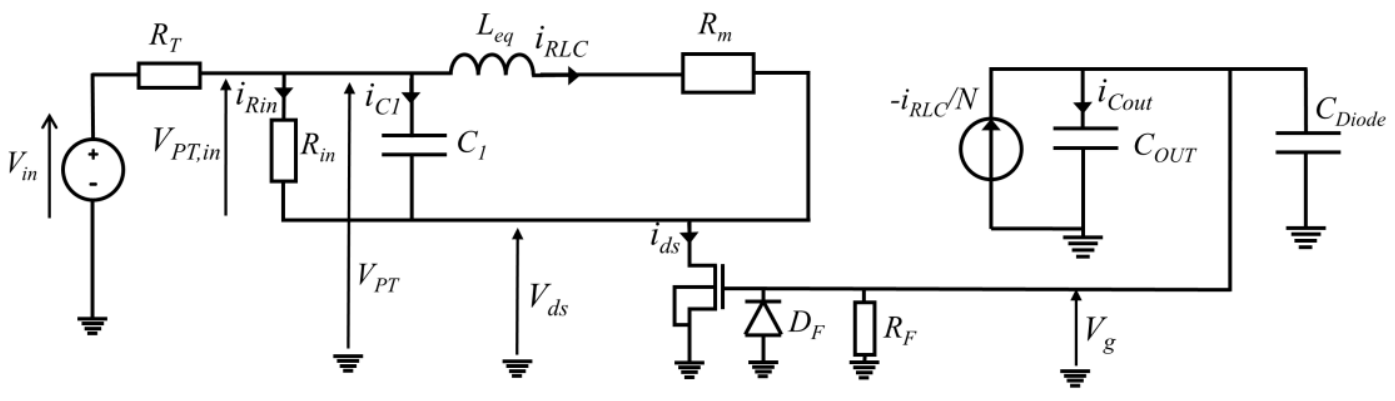

Fig. 8: Steady-state analysis simplified circuit 
For the classical transistor model and considering assumption 6, we have:

$$
\left\{\begin{array}{c}
i_{d s, \text { cutoff }}=0 \text { if } V_{g}<V_{t} \\
i_{d s \text {,linear }}=\beta\left(2\left(V_{g}-V_{t h}\right)-V_{d s}\right) V_{d s} \text { if } V_{g}>V_{t}
\end{array}\right.
$$

During a period of steady-state oscillation, the transistor will switch operating region when $\mathrm{V}_{\mathrm{g}}>\mathrm{V}_{\text {th }}$. We define $\theta=$ $\omega_{\text {osc }} t$ and $\theta_{c}=\omega_{\text {osc }} t_{c}$ as the angle at which the change of region takes place (fig.8). At the boundary between the two operating regions, we have $V_{g, c}=V_{t h}$ which leads to

$$
\cos \left(\theta_{c}\right)=\frac{V_{t h}-V_{D}}{V_{A}}
$$

The current flowing through the transistor is periodic with a fundamental pulsation $\omega_{\text {osc }}$. It can thus be represented by a Fourier series such as:

$$
i_{d s}=i_{d s, D C}+\sum_{k \geq 1} i_{d s, i} \cos \left(k \omega_{o s c} t\right)
$$

The values of $i_{d s, k}$ and $i_{d s, D C}$ are then defined using the formula for Fourier coefficients and the current equation:

$$
\begin{aligned}
i_{d s, D C} & =\frac{1}{2 \pi} \int_{0}^{2 \pi} i_{d s} d \theta \\
& =\frac{\beta}{\pi} \int_{0}^{\theta_{c}} V_{d s}\left(2\left(V_{g}-V_{t h}\right)-V_{d s}\right) d \theta \\
i_{d s, k} & =\frac{1}{\pi} \int_{0}^{2 \pi} i_{d s} \cos (k \theta) d \theta \\
& =\frac{2 \beta}{\pi} \int_{0}^{\theta_{c}} V_{d s} \cos (k \theta)\left(2\left(V_{g}-V_{t h}\right)-V_{d s}\right) d \theta
\end{aligned}
$$

In (21) and (22), the Fourier coefficients of $i_{d s}$ are determined by the equations of the transistor. Those coefficients are also defined by equation (16) and the values of $i_{R_{i n}}, i_{C_{1}}$ and $i_{R L C}$ determined in (12), (14) and (15). If, in the analysis, we consider $n-1$ harmonics, the equalization of those coefficients results in a system of $n+1$ equations with $n+1$ unknowns. The equations correspond to the DC value, the fundamental coefficient and the n-1 harmonics. The unknowns are the value of the cutoff angle $\theta_{c}$, the DC value $V_{B}$ of $V_{\text {in }}$ and the values of $\mathrm{V}_{\mathrm{k}} \cdot \mathrm{V}_{\mathrm{A}}$ can be extracted from $\theta_{c}$. As it is only interesting to determine $\mathrm{V}_{\mathrm{B}}$ and $\theta_{c}$, we just consider the system composed of the two equations for the DC and fundamental values of $i_{\text {ds. }}$.

The diagram of the implemented numerical resolution is represented in Fig.9. All the equations and the model are implemented in order to define the values of the currents $i_{d s}$. The solver will then numerically solve the system of equations for $i_{d s}$ and determine the values $V_{b}$ and $\theta_{c}$. The results of this analysis will be discussed and compared to time-domain simulation results and experimental measurements in section V.

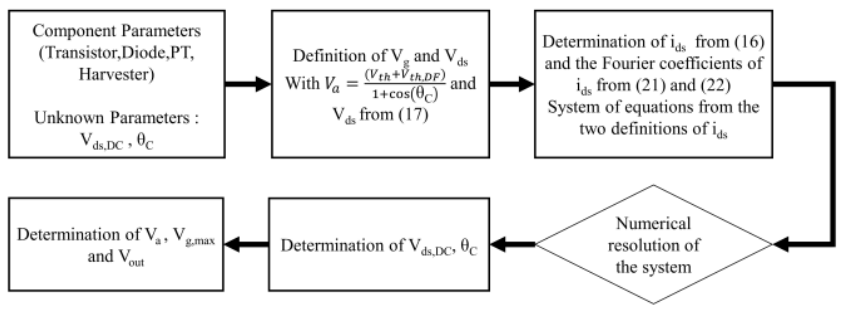

Fig. 9 : Diagram of the numerical resolution of the steady-state analytical model

\section{EXPERIMENTAL MEASUREMENTS}

\section{A. Setup description}

The components used for the realization of the converter are chosen to validate the concept and the circuit model but not to completely optimize the performances. Typically, only a few manufacturers offer multilayer Rosen PT's and these are in general for high-voltage applications and not designed for start-up converters. The PT is still chosen as a multilayer Rosen-type transformer that has an ideal transformer ratio of 58.8 and output capacitance of several $\mathrm{pF}$ to reach a higher voltage gain. The selected depletion mode MOSFET, a normally-ON transistor, i.e. with negative threshold voltage, allows the oscillation to start when the gate voltage is equal to zero. The input capacitance is also chosen as small as possible and the threshold voltage close to $0 \mathrm{~V}$. In fact, from the transconductance equations presented in (7), it appears that the transconductance of the transistor is at a maximum when the drain-source voltage is equal and opposite to the threshold voltage. The latter is then chosen to be close to $0 \mathrm{~V}$ to have maximum transconductance for lower input voltages to start easily at those small voltages. Finally, the rectifier is a series diode topology with low capacitance Schottky diode to limit its contribution to the output capacitance. All the components parameters are summarized in Table I.

The complete prototype on PCB is shown in Fig. 10. The PCB design has to be done to minimize the parasitic capacitances in order to maximize the voltage gain. Operational amplifiers are added in the circuit as buffers to limit the effect of the $10 \mathrm{M} \Omega$ impedance of the oscilloscope probes. The operational amplifier chosen is a TL082 with a JFET input so the input impedance is $1 \mathrm{~T} \Omega$. However, it still exhibits an input capacitance that degrades the performance when directly connected to the gate. Measurements were firstly realized with a $1 \mathrm{nF}$ storage capacitance to quickly measure the start-up and output voltages. The complete circuit of the test bench is represented in Fig.11. The signals $\mathrm{V}_{\mathrm{g}}$ and $\mathrm{V}_{\text {out }}$ in steady-state are observed on an oscilloscope and are depicted in Fig.12. The observation of these signals confirm the hypothesis made during the modelling. The DC value of $\mathrm{V}_{\mathrm{g}}$ in steady-state is different from 0 due to the diode present in the transistor. 


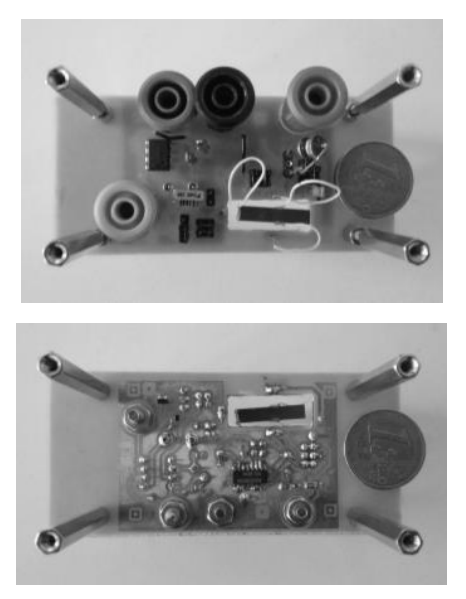

Fig. 10: PCB of the proposed start-up converter.

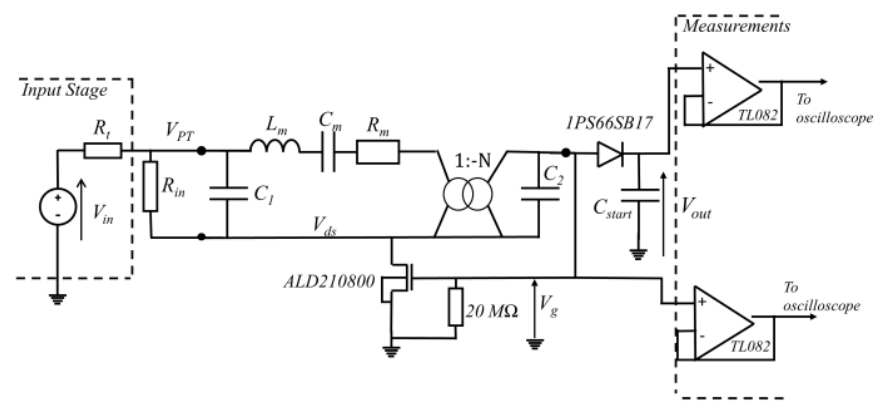

Fig. 11: Circuit of the experimental test bench

Finally, the measurements are realized with a thermoelectric generator whose harvester internal resistance is of 2.8 $\Omega$. The Seebeck coefficient of the TEG is of $6 \mathrm{mV} / \mathrm{K}$. A temperature gradient is applied to the TEG and thus a voltage appears at the output of the harvester. The change in the gradient of temperature will change proportionally the value of this voltage $\mathrm{V}_{\mathrm{in}}$. The harvester output is then connected to the input of the start-up converter. If the temperature gradient applied is smaller than $17 \mathrm{~K}$ then the voltage at the input of the converter will be lower than $100 \mathrm{mV}$ confirming the necessity for a start-up converter.

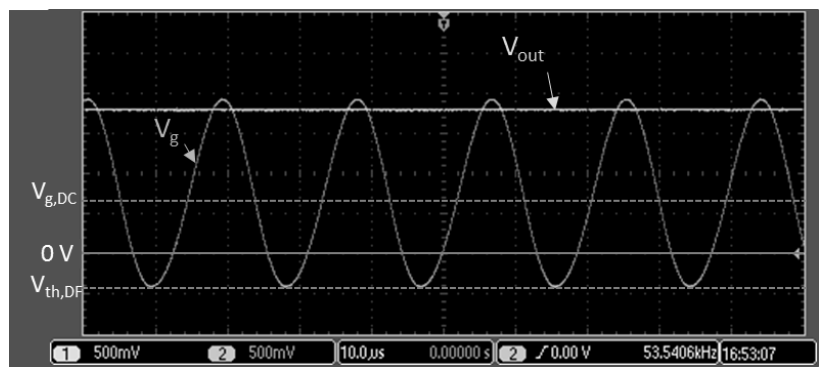

Fig. 12 : Signal waveforms of $\mathrm{V}_{\text {out }}$ and $\mathrm{V}_{\mathrm{g}}$ in steady-state

\section{B. Measurements}

In a first step, the step-up performances and the sensitivity to $R_{\text {in }}$ values have been characterized with a TEG. The TEG is placed between two metal plates: one is in contact with a heatsink and the other one with a transistor that increases the temperature. The voltage generated by the TEG $V_{\text {in }}$ is monitored at the input of the converter. Fig. 13 shows the output voltage for different biasing resistances $R_{\text {in }}$ as a function of the input voltage $\mathrm{V}_{\text {in }}$. For a biasing resistance of $390 \Omega$, the output voltage reaches $1 \mathrm{~V}$ for input voltages as low as $43 \mathrm{mV}$. In this configuration, the oscillation starts for an input voltage of $25 \mathrm{mV}$ and the output reaches $400 \mathrm{mV}$. On the other hand, in the case of a $2200 \Omega$ biasing resistance, oscillation will start when $V_{\text {in }}$ is equal to $15 \mathrm{mV}$ but will only reach $1 \mathrm{~V}$ at an input voltage of $82 \mathrm{mV}$. For input voltages higher than $50 \mathrm{mV}$, the value of the biasing resistance is directly related to the output voltage value: when the biasing resistance gets smaller, the circuit presents a higher voltage gain. At smaller input voltages the influence of the biasing resistance $R_{i n}$ on the output voltage is not as clear. Indeed, in a configuration with smaller biasing resistance, the oscillation may not start at ultra-low voltages. For example, at $30 \mathrm{mV}$, the circuit with a biasing resistance of $680 \Omega$ presents a higher voltage gain than the ones with $R_{\text {in }}=390 \Omega$ and $R_{\text {in }}=2200 \Omega$.

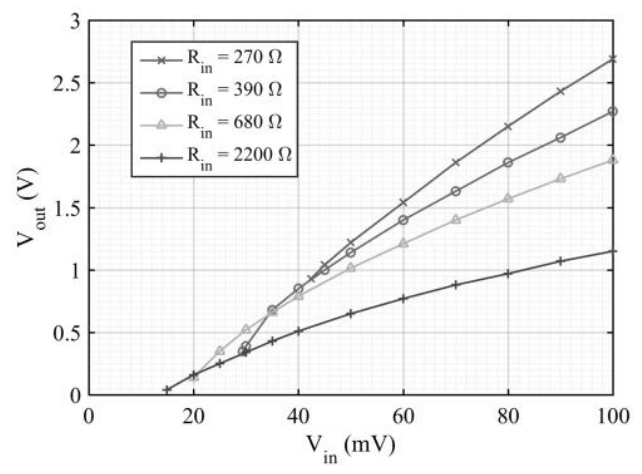

Fig. 13: Measured voltage gain as a function of $V_{\text {in }}$ for different values of $R_{\text {in }}$

In this part we have been interested in characterizing the minimum values of $\mathrm{V}_{\text {in }}$ leading to start the oscillation. Fig. 14 shows the minimum input voltage at which we begin to see a charging of a capacitance as a function of $R_{i n}$. The gain of the converter $\frac{\mathrm{V}_{\text {out }}}{\mathrm{V}_{\text {in }}}$ at the start-up voltage is also presented. The start-up voltage can be as low as $15 \mathrm{mV}$ for a biasing resistance of $2 \mathrm{k} \Omega$. At a lower resistance, the circuit starts at higher input voltages. Here, we also observe an optimum value for the biasing resistance that minimizes the start-up voltage. On the other hand, even though oscillations start at this voltage, the gain is only equal to 2 leading to a very low output voltage which fails to start the main converter shown in Fig. 1. The output voltage at start-up will generally be lower as the biasing resistance increases. As the open-loop gain $\mathrm{G}_{\mathrm{OL}}$ will grow with $R_{\text {in }}$ by equation (9), when the biasing resistance is small, $\mathrm{G}_{\mathrm{OL}}$ will be smaller and the oscillation won't start at low voltages due to the Barkhausen criterion. On the other hand, if the resistance becomes too large, the drain-source voltage of the transistor decreases and so the transconductance decreases as seen in (7) leading to a decrease in the open-loop gain $\mathrm{G}_{\mathrm{OL}}$. Finally, those two behaviors lead to an optimum value for $\mathrm{R}_{\mathrm{in}}$ that minimizes the start-up voltage. 


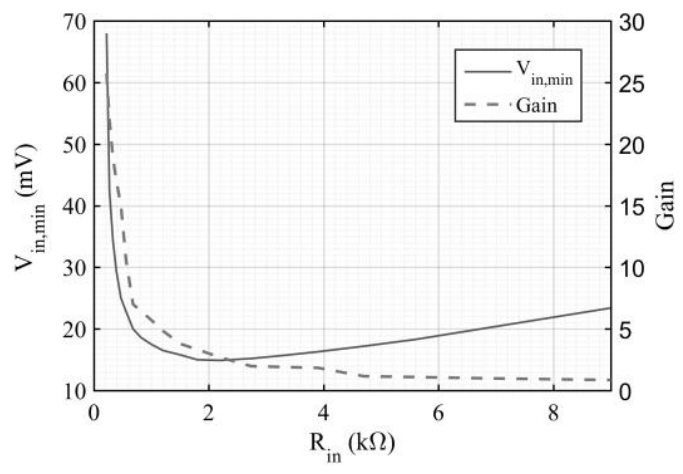

Fig. 14: Measured minimum start-up voltage and gain $\mathrm{V}_{\text {out }} / \mathrm{V}_{\text {in }}$ of the converter at the start-up voltage for different biasing resistances

Finally, the start-up performances can be summarized in Table II. Herein are represented the start-up voltages and the minimum values of the input voltage to reach an output voltage of $1 \mathrm{~V}$. Indeed, the function of the circuit is to charge a storage capacitor at a certain voltage in order to start the main DC-DC converter. Thus, an important parameter in the design is to obtain the minimum input voltage at which the output will reach this threshold voltage that will start the main converter. In this case, we choose arbitrary a value of $1 \mathrm{~V}$ for the threshold voltage. The minimum values for each parameter are in bold. The optimum biasing resistance values for the start-up and voltage gain are different. Moreover, the minimum value of $\mathrm{V}_{\text {in }}$ to reach $\mathrm{V}_{\text {out }}=1 \mathrm{~V}$ is dependent on the start-up voltage. For a biasing resistance of $220 \Omega$, the circuit only starts at $68 \mathrm{mV}$ and at this voltage, $\mathrm{V}_{\text {out }}=1.75 \mathrm{~V}$ whereas with $R_{\text {in }}=270 \Omega$, the circuit starts at lower voltages and can reach an output voltage of $1 \mathrm{~V}$ at $\mathrm{V}_{\text {in }}=43 \mathrm{mV}$. In the end, the choice of the biasing resistance value will depend on the voltage across $\mathrm{C}_{\text {start }}$ needed to start the optimized converter.

\section{DISCUSSION}

\section{A. Model validation}

The experimental realization presented in the previous section validates the behavior of the start-up converter. In order to validate the models, we will compare the results obtained with the analytical modeling, the electrical simulations based on components models given by the manufacturers and the experimental measurements. The timedomain simulations were realized with LTSpice where the circuit presented in Fig. 4 was used. All the values used for the simulation are the ones presented in Table I. The models of the transistor and the diode were given directly by the manufacturer. The analytical modeling was implemented in
Matlab as presented in III.

The results of the start-up phase analysis were not considered in terms of start-up voltage as the Barkhausen criterion classically used in the analysis is only necessary but insufficient in determining the start of the oscillation. In fact, the minimum start-up voltages determined numerically were much lower than the ones measured. The start-up phase analysis is still useful in order to have a better understanding of the behavior of the converter and the trade-off of the different parameters in the start-up.

In steady state, the maximum output voltage was extracted directly from the LTSpice simulation and compared to the Matlab analytical results and experiments. Fig. 15 presents the comparison of the three different approaches (analytical/Spice simulations/measurements) for biasing resistances of $270 \Omega$ and $1000 \Omega$.

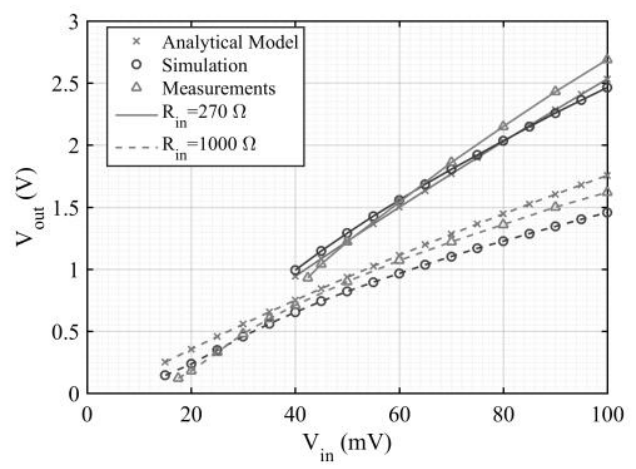

Fig. 15: Comparison of the output voltage given by the analytical model, simulation and measurements

As can be seen from Fig. 15, the results of the numerical analysis, simulation and measurements are similar and follow the same behavior. However, there are differences in absolute value between the three results. For the two $R_{\text {in }}$ values, the simulation tends to give lower output voltage than the measurements. For the analytical model, it depends on the biasing resistance value $R_{i n}$ but in the range from 40 to $70 \mathrm{mV}$ it fits quite well the experimental results. The errors between the analytical model results and measurements are $5.8 \%$ and $8.3 \%$ for respectively the cases $R_{\text {in }}=270 \Omega$ and $R_{\text {in }}=1000 \Omega$. Between the simulation and measurements the errors are respectively $8.3 \%$ and $10 \%$. The differences in the values have several origins. The minimum value of $\mathrm{V}_{\mathrm{g}}$ defined by the transistor diode threshold voltage changes as a function of the input voltage in the simulation and experimentation but assumed as constant in the analytical model.

TABLE II

MEASUREMENT RESULTS

\begin{tabular}{|c|c|c|c|c|c|c|c|c|c|c|c|c|c|c|c|}
\hline $\mathrm{R}_{\text {in }}(\Omega)$ & 220 & 270 & 330 & 390 & 470 & 560 & 680 & 820 & 1000 & 1200 & 1500 & 1800 & 2200 & 2700 & 3300 \\
\hline $\begin{array}{c}\text { Start-up voltage } \\
(\mathrm{mV})\end{array}$ & 68 & 42,4 & 34,4 & 29,4 & 25 & 22,8 & 20 & 18,6 & 17,5 & 16,5 & 15,8 & $\mathbf{1 5}$ & $\mathbf{1 5}$ & 15,2 & 15,7 \\
\hline $\begin{array}{c}\mathrm{V}_{\text {in }}(\mathrm{mV}) \text { to obtain } \\
\mathrm{V}_{\text {out }}=1 \mathrm{~V}\end{array}$ & 68 & $\mathbf{4 3}$ & 44 & 45 & 46 & 47,5 & 49 & 53 & 57 & 61 & 68 & 73 & 82 & 95 & 107 \\
\hline
\end{tabular}


This leads to a different DC value for the gate voltage. The drain-source capacitance is not considered. In addition, the analysis was realized considering a four-point electrode PT whereas a three-point one is used in the simulation and experimental realization. The parameters used in the analytical model and the LTSpice simulations were determined experimentally. More specifically, the parameters of the PT come from impedance measurements and may not reflect the real parameters of the PT and the load capacitance was estimated from the capacitance of the copper tracks and the different parasitic capacitance that influence the value of $\mathrm{C}_{\text {out }}$. Finally, errors also come from the measurements themselves.

\section{B. Influence of the harvester internal resistance}

A RF energy harvester consists of a rectenna that provides a DC voltage from electromagnetic energy harvesting. These system's internal resistance depend on the rectenna topology but will typically present internal resistances $R_{h}$ of 100 to $1000 \Omega$ [13]. We add resistances of 240 and $1000 \Omega$ in series between the TEG's output and the input of the converter in order to emulate the behavior of a rectenna. The measurements obtained with an input voltage of $100 \mathrm{mV}$ are represented in Fig 16 (a). Results show that the circuit still works with higher internal resistance and thus with smaller input power available. Indeed, at a voltage of $100 \mathrm{mV}$ the maximum powers available at the input are respectively 893 $\mu \mathrm{W}, 11.4 \mu \mathrm{W}$ and $2.5 \mu \mathrm{W}$ for internal resistances of $2.8 \Omega$, $240 \Omega$ and $1000 \Omega$. With $\mathrm{R}_{\mathrm{t}}=240 \Omega$, the output reaches a value of $1.7 \mathrm{~V}$ and $900 \mathrm{mV}$ for $\mathrm{R}_{\mathrm{t}}=1000 \Omega$.

The curves of Fig. 16 (a) also demonstrate the presence of an optimum value for the biasing resistance to maximize the output voltage. This optimum depends on the value of the harvester resistance. For the case $R_{t}=1000 \Omega$, the optimum voltage appears with a biasing resistance $R_{\text {in }}$ value close to $R_{t}$

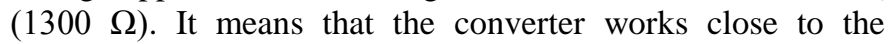
maximum power operating point and will thus provide the highest voltage at the output. For the case $R_{t}=240 \Omega$, the maximum voltage is obtained with an biasing resistance of $560 \Omega$. The optimum value of $R_{\text {in }}$ is different from $R_{t}$ so the converter does not work close to the maximum power point. In this case, we observe that as the resistance increases the DC value of $V_{d s}$ will be smaller and the current flowing in the transistor will also decrease. On the other hand, a larger biasing resistance also means a larger input voltage for the same current. These two behaviors lead to an optimum value of the biasing resistance that gives the highest voltage at the input of the piezoelectric transformer and thus the highest output voltage. Finally, for the case $\mathrm{R}_{\mathrm{t}}=2.8 \Omega$, the optimum value of $R_{\text {in }}$ is the lower resistance at which the circuit starts as the optimum value for the gain if the circuit started for all values of $R_{\text {in }}$ would be close to the value of $R_{t}$.

The evolution of the output voltage $V_{\text {out }}$ for the three different configurations as a function of the input voltage $V_{\text {in }}$ is shown in Fig. 16 (b) for a biasing resistance value $R_{\text {in }}$ of $2200 \Omega$. This resistance represents the optimum biasing resistance that minimizes the start-up voltage for the three cases. With this set-up, the circuit with $\mathrm{R}_{\mathrm{t}}=2.8 \Omega$ starts at the minimum voltage as the power extracted from the harvester is higher. Nevertheless, the output voltage with $R_{\text {in }}=2200 \Omega$ is not optimum and the output voltage reaches $1 \mathrm{~V}$ for the same input voltage of $83 \mathrm{mV}$ for the cases $R_{t}=2.8 \Omega$ and $R_{t}=240$ $\Omega$. The voltage gains are quite similar for these two cases. Indeed, the circuit works far away from the maximum power point so the difference in maximum power available for these two configurations doesn't have a big impact on the voltage gain.
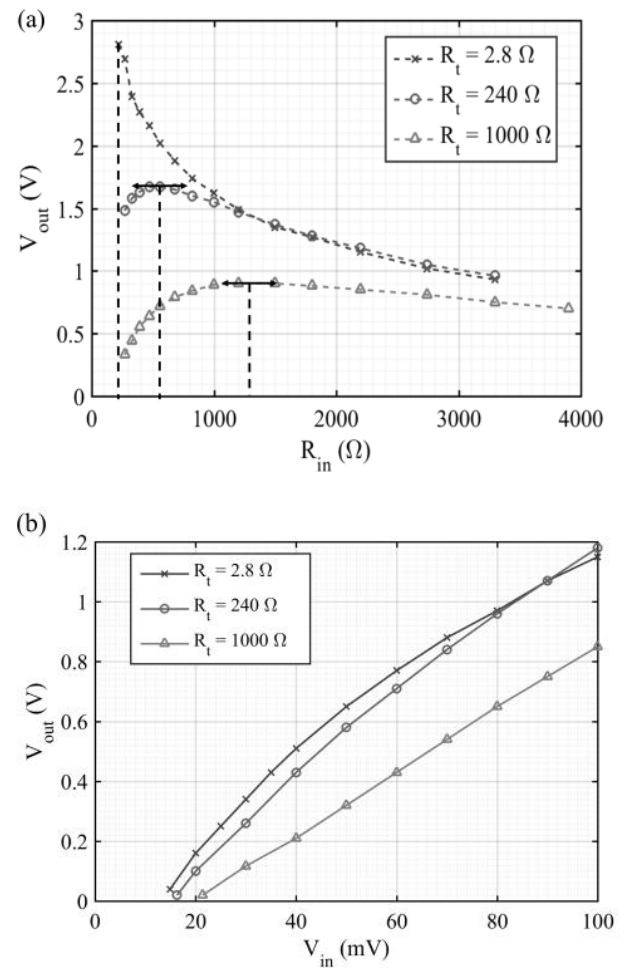

Fig. 16: Output voltage gain for different harvester resistances (a) as a function of $R_{\text {in }}$ and for Vin $=100 \mathrm{mV}$ and (b) as a function of Vin for a biasing resistance $\mathrm{R}_{\text {in }}=2200 \Omega$

\section{1) Start-up voltage}

The definition of the start-up voltage for ultra-low voltage start-up converters unfortunately still needs to be clarified. The start-up voltage is generally defined as the one where the step-up function starts and a voltage is observed at the output. In this paper, this definition was chosen. However, we can question the validity of such a definition. Let us recall that the main objective of the start-up converter is to accumulate enough energy at a certain voltage at the output in order to start the main converter (Fig. 1). Nevertheless, the problem resides in the definition of the targeted output voltage to start a main converter. Some papers define this as $500 \mathrm{mV}$ above the threshold voltage of the transistors used [22] while others prefer a fixed output voltage objective of $1 \mathrm{~V}$, for example in [16]. The former definition is interesting as it is precise and identical for all start-up circuits and it allows comparison of performance of converters but it does not reflect the principal function of the start-up converter. For the circuit presented herein, the oscillation can start at a voltage as low as $15 \mathrm{mV}$ with a sufficient resistance at the input. On the other hand, in this configuration, the circuit will only reach $1 \mathrm{~V}$ at an input voltage of $73 \mathrm{mV}$. For a biasing resistance of $390 \Omega$, the 
circuit will start at only $29.4 \mathrm{mV}$ but reaches $1 \mathrm{~V}$ with an input voltage of only $45 \mathrm{mV}$.

\section{2) Power efficiency}

As stated in the introduction, the efficiency of the start-up converter was not a key parameter. The efficiency only affects the time to reach the maximum voltage at the output. Fig. 17 shows the charging of a $4.7 \mu \mathrm{F}$ capacitor when the input voltage is set at $100 \mathrm{mV}$ for a harvester resistance of $2.8 \Omega$. The biasing resistance value $\mathrm{R}_{\text {in }}$ is $560 \Omega$. We observe three phases during the charge of the capacitor. The first corresponds to the start-up phase analysis where the transistor has a linear behavior (1 on Fig. 17). At some point, the gate voltage reaches the threshold voltage of the transistor and the circuit enters the transition phase where the classical RC behavior appears (2). Finally, when the capacitor is charged, the converter reaches the steady-state (3). The time needed to charge the capacitor then defines the power harvested at the output.

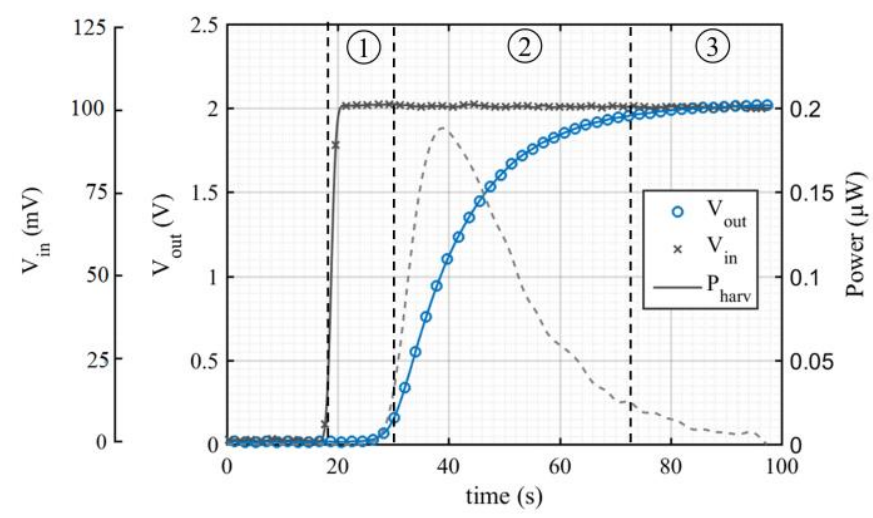

Fig. 17: Charge of the $4.7 \mu \mathrm{F}$ storage capacitance for an input voltage of 100 $\mathrm{mV}$ and a biasing resistance of $560 \Omega$

In Fig. 17 is also represented the instantaneous power $P_{\text {harv }}=C_{\text {start }} V_{\text {out }} \frac{d V_{\text {out }}}{d t}$ as a function of time. We observe that the maximum instantaneous power is obtained during the transition phase and reaches the maximum value of $0.19 \mu \mathrm{W}$. Considering the harvester resistance $\mathrm{R}_{\mathrm{t}}$ of $2.8 \Omega$ and the input voltage $\mathrm{V}_{\text {in }}$ of $100 \mathrm{mV}$, the maximum power available from the harvester is equal to $893 \mu \mathrm{W}$. The power harvested allows the capacitance to charge but in permanent state, the power at output compensates only the losses in the insulation resistance $\mathrm{R}_{\text {start }}$. If we consider a typical insulation resistance of 3700 $\mathrm{M} \Omega$, the power consumed at the output is only $1 \mathrm{nW}$ but the important parameter is the total energy stored in the capacitance $\mathrm{C}_{\text {start }}$. The power harvested is much lower as the converter was not designed for efficiency requirements but to obtain the highest voltage gain. Moreover, in the architecture itself, the biasing resistance dissipates power that makes the converter difficult to reuse for an optimized conversion application. On the other hand, the presence of the biasing resistor $R_{\text {in }}$ allows more versatility for adaptation to any type of harvester with higher internal resistance $R_{t}$, insuring the start of the converter proposed in this paper. Finally, a solution to obtain the maximum power would be to adjust the value of the biasing resistance $R_{\text {in }}$ as a function of $V_{\text {out }}$ to adapt better the impedance as seen from the input of the start-up converter.

\section{Comparison with other start-up converter topologies.}

The performances of different start-up converters are summarized in Table III. Compared to other inductor-less solutions, our converter achieves lower start-up and higher voltage gain especially compared to which also uses a resonant oscillator topology with a piezoelectric transformer. [23] consists of the same topology as the one proposed in the paper but with a biasing inductance as a replacement of the biasing resistance. This solution achieves better performances but uses an inductance that could be problematic in applications with EMC issues and potentially difficult to integrate with micro-electronic techniques. [10] presents a lower start-up but uses an external mechanical vibration to kick-start the boost converter which also uses an inductance. [14] and [12] achieve better voltage gain but uses bulky magnetic transformers that are hardly shrinkable and may induce electromagnetic issues in the circuit. Finally, the solution proposed in [15] has overall better performances in a similar area of PCB than our solution but still uses inductance of $1 \mathrm{mH}$ and moreover our converter is almost completely planar. Furthermore, the circuit we propose was designed with off-the-shelf components in order to validate the concept of the converter and not with a complete optimization of all components to obtain the best performances. Especially, the piezoelectric transformer is oversized compared to the power that it converts. Finally, our converter can theoretically work with other energy harvester than TEG which present higher internal resistance.

\section{CONCLUSION}

The proposed inductor-less start-up converter for energy harvesting applications consists of an Armstrong oscillator architecture with a piezoelectric transformer and a normallyON depletion mode MOSFET. The circuit improves the minimum input voltage to start oscillations and voltage gain of inductor-less start-up converters. The modeling of the circuit allows us to predict the oscillation frequency of the converter and the output voltage as a function of all the circuit parameters. With the help of an analytical model, a complete optimization of the components used in the converter is made possible. The experimental converter is realized using off-theshelf components and it validates the model of the converter. For typical thermal energy harvester values, the circuit starts to work at voltages as low as $15 \mathrm{mV}$ and the output voltage reaches $1 \mathrm{~V}$ for a $43 \mathrm{mV}$ input voltage. Furthermore, the converter shows versatility as it is also suitable when the harvester internal resistance is higher. For example, with a harvester resistance of $240 \Omega$, the output voltage reaches $1 \mathrm{~V}$ for an input voltage of $73 \mathrm{mV}$. The use of full-custom designed piezoelectric transformers and MOSFET's could further improve the performances. 
TABLE III

COMPARISON BETWEEN START-UP CONVERTER TOPOLOGIES

\begin{tabular}{|c|c|c|c|c|c|}
\hline Ref. & Converter architecture & Particular elements & $\begin{array}{l}\text { Analytical } \\
\text { Models }\end{array}$ & $\begin{array}{l}\text { Minimum start-up } \\
\text { voltage }(\mathrm{mV})\end{array}$ & $\begin{array}{l}\text { Minimum } V_{\text {in }} \text { to obtain } \\
\mathrm{V}_{\text {out }}=1 \mathrm{~V}(\mathrm{mV})\end{array}$ \\
\hline [9] & Inductor-less Charge pump & No & No & 200 & 250 \\
\hline$[10]$ & Boost & $\begin{array}{c}\text { Mechanical switch + external } \\
\text { vibration }\end{array}$ & No & 35 & 35 \\
\hline$[15]$ & $\begin{array}{c}\text { Ultra low voltage oscillator } \\
\text { and charge pump }\end{array}$ & $1 \mathrm{mH}$ inductance & $\begin{array}{l}\text { Start-up and } \\
\text { steady-state }\end{array}$ & 10 & 10 \\
\hline$[14]$ & Resonant oscillator & $\begin{array}{c}7 \text { magnetic transformers in } \\
\text { series }\end{array}$ & No & 6 & 6 \\
\hline [12] & Resonant oscillator & Magnetic transformer & Start-up & 40 & 40 \\
\hline$[22]$ & Resonant oscillator & $\begin{array}{c}\text { Piezoelectric transformer + } \\
\text { biasing inductance }\end{array}$ & Start-up & 32 & 46 \\
\hline$[22]$ & $\begin{array}{c}\text { Inductor-less resonant } \\
\text { oscillator }\end{array}$ & Piezoelectric transformer & Start-up & 69 & 69 \\
\hline$[23]$ & Resonant oscillator & $\begin{array}{l}\text { Piezoelectric transformer }+ \\
\text { inductor }\end{array}$ & Start-up & 12 & 18 \\
\hline $\begin{array}{l}\text { This } \\
\text { Work }\end{array}$ & $\begin{array}{l}\text { Inductor-less resonant } \\
\text { oscillator }\end{array}$ & $\begin{array}{c}\text { Piezoelectric transformer }+ \\
\text { biasing resistance }\end{array}$ & $\begin{array}{l}\text { Start-up and } \\
\text { steady-state }\end{array}$ & 15 & 43 \\
\hline
\end{tabular}

\section{REFERENCES}

[1] C. Knight, J. Davidson, and S. Behrens, "Energy Options for Wireless Sensor Nodes," Sensors, vol. 8, no. 12, pp. 8037-8066, Dec. 2008.

[2] R. J. M. Vullers, R. van Schaijk, I. Doms, C. Van Hoof, and R. Mertens, "Micropower energy harvesting," SolidState Electron., vol. 53, no. 7, pp. 684-693, Jul. 2009.

[3] S.-E. Adami, "Optimisation de la récupération d'énergie dans les applications de rectenna.", Ph. D.

Dissertation Ecole centrale de Lyon, Ecully, France, 2013.

[4] S. Bandyopadhyay and A. P. Chandrakasan, "Platform Architecture for Solar, Thermal, and Vibration Energy Combining With MPPT and Single Inductor," IEEE J. Solid-State Circuits, vol. 47, no. 9, pp. 2199-2215, Sep. 2012.

[5] A. Richelli, L. Colalongo, S. Tonoli, and Z. M. KovÁcsVajna, "A 0.2 V DC/DC Boost Converter for Power Harvesting Applications," IEEE Trans. Power Electron., vol. 24, no. 6, pp. 1541-1546, Jun. 2009.

[6] J. Kim and C. Kim, "A DC-DC Boost Converter With Variation-Tolerant MPPT Technique and Efficient ZCS Circuit for Thermoelectric Energy Harvesting Applications," IEEE Trans. Power Electron., vol. 28, no. 8, pp. 3827-3833, Aug. 2013.

[7] M. Dini, A. Romani, M. Filippi, and M. Tartagni, "A Nanocurrent Power Management IC for Low-Voltage Energy Harvesting Sources," IEEE Trans. Power Electron., vol. 31, no. 6, pp. 4292-4304, Jun. 2016.

[8] P.-H. Chen et al., "0.18-V input charge pump with forward body biasing in startup circuit using $65 \mathrm{~nm}$ CMOS," in 2010 IEEE Custom Integrated Circuits Conference (CICC), 2010, pp. 1-4.

[9] G. Pillonnet and T. Martinez, "Sub-threshold startup charge pump using depletion MOSFET for a low-voltage harvesting application," in 2015 IEEE Energy Conversion Congress and Exposition (ECCE), 2015, pp. 3143-3147.

[10] Y. K. Ramadass and A. P. Chandrakasan, "A BatteryLess Thermoelectric Energy Harvesting Interface Circuit With $35 \mathrm{mV}$ Startup Voltage," IEEE J. Solid-State Circuits, vol. 46, no. 1, pp. 333-341, Jan. 2011.

[11] E. H. Armstrong, "Wireless receiving system.," US 1113149 A, 06-Oct-1914.

[12] J. P. Im et al., "A 40mV transformer-reuse self-startup boost converter with MPPT control for thermoelectric energy harvesting," in 2012 IEEE International SolidState Circuits Conference, 2012, pp. 104-106.

[13] S.-E. Adami et al., "Ultra-Low Power, Low Voltage, Self-Powered Resonant DC-DC Converter for Energy Harvesting," J. Low Power Electron., vol. 9, no. 1, pp. 103-117, Apr. 2013.

[14] D. Grgić, T. Ungan, M. Kostić, and L. M. Reindl, "Ultralow input voltage DC-DC converter for micro energy harvesting," in PowerMeMs, 2009, pp. 265-268.

[15] M. B. Machado, M. Sawan, M. C. Schneider, and C. Galup-Montoro, " $10 \mathrm{mV}$ - $1 \mathrm{~V}$ step-up converter for energy harvesting applications," in 27th Symposium on Integrated Circuits and Systems Design (SBCCI), 2014, pp. 1-5.

[16] G. Bassi, L. Colalongo, A. Richelli, and Z. M. KovacsVajna, "100 mV-1.2 V fully-integrated DC -DC converters for thermal energy harvesting," IET Power Electron., vol. 6, no. 6, pp. 1151-1156, Jul. 2013.

[17] E. Wells, "Comparing magnetic and piezoelectric transformer approaches in CCFL applications," Analog Appl J, no. Q1, pp. 12-17, 2002.

[18] S. S. Bedair, J. S. Pulskamp, R. G. Polcawich, B. Morgan, J. L. Martin, and B. Power, "Thin-Film Piezoelectric-on-Silicon Resonant Transformers," $J$. Microelectromechanical Syst., vol. 22, no. 6, pp. 13831394, Dec. 2013. 
[19] D. Vasic, F. Costa, and E. Sarraute, “Comparing piezoelectric and coreless electromagnetic transformer approaches in IGBT driver," Eur. Phys. J. - Appl. Phys., vol. 34, no. 3, pp. 237-242, 2006.

[20] M. W. Hooker, "Properties of PZT-based piezoelectric ceramics between- 150 and $250{ }^{\circ} \mathrm{C}$," Technical report NASA/CR-208708, 1998.

[21] D. Vasic, “Apports des matériaux piézoélectriques pour l'intégration hybride et monolithique des transformateurs." Ph.D. Dissertation, Ecole normale supérieure, Cachan, France, 2003.

[22] A. Camarda, A. Romani, E. Macrelli, and M. Tartagni, "A $32 \mathrm{mV} / 69 \mathrm{mV}$ input voltage booster based on a piezoelectric transformer for energy harvesting applications," Sens. Actuators Phys., vol. 232, pp. 341352, Aug. 2015.

[23] T. Martinez, G. Pillonnet, and F. Costa, "A 12 mV startup converter using piezoelectric transformer for energy harvesting applications," J. Phys. Conf. Ser., vol. 773, no. 1, p. 12028, 2016.

[24] E. M. Syed, F. P. Dawson, and E. S. Rogers, "Analysis and modeling of a Rosen type piezoelectric transformer," in Power Electronics Specialists Conference, 2001. PESC. 2001 IEEE 32nd Annual, 2001, vol. 4, pp. 17611766.

[25] W. Zhiming, Y. Xinghong, and J. Y. X. Guangzhong, "The analysis of multilayer piezoelectric transformer," in 2005 12th International Symposium on Electrets, 2005, pp. 165-167.

[26] "Multi Layer Piezo Transformer Step Up Ratio 45 SMMTF53P3S45- STEMINC." [Online]. Available: https://www.steminc.com/PZT/en/piezo-transformer-55khz-3w. [Accessed: 23-May-2016].

[27] "ALD210800 - ALD210800.pdf." [Online]. Available: http://www.aldinc.com/pdf/ALD210800.pdf..

[28] K. Mayaram, "Output voltage analysis for the MOS Colpitts oscillator," IEEE Trans. Circuits Syst. Fundam. Theory Appl., vol. 47, no. 2, pp. 260-263, Feb. 2000.

T. Martinez was born in Montluçon, France in 1992. He received an Engineering degree in Electrical Engineering from Ecole Polytechnique in 2015 and a M. Sc degree in Micro and Nano Electronics from the Ecole Polytechnique Federale de Lausanne in 2016. He joined the SATIE laboratory for his Master Thesis in 2015 where he is currently working on his $\mathrm{Ph}$. D. thesis. His current research interest include low power electronics for energy harvesting and piezoelectric devices for energy conversion.

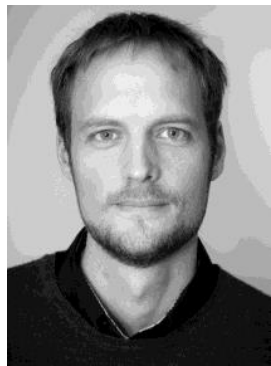

G. Pillonnet was born in Lyon, France, in 1981. He received his Master degree in Electrical Engineering from CPE Lyon, France in 2004, a PhD and habilitation degrees from INSA Lyon, France in 2007 and 2016 respectively. Following an early experience as analog designer in STMicroelectronics in 2008, he joined University of Lyon in the Electrical Engineering department. During the 2011-12 academic year, he held a visiting researcher position at the University of California at Berkeley. Since 2013, he has worked as full-time researcher at the CEA-LETI, a major French research institution. His research focuses on low power electronics using heterogeneous devices including modeling, circuit design and control techniques. He has published more than 70 papers in his areas of interest.

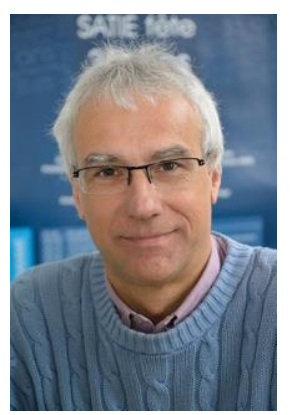

F. Costa received the Ph.D. in electrical engineering, entitled "EMI in HF power electronics" from the University of Paris-Sud, Orsay, France, in 1992 and the "Habilitation à diriger des recherches (HDR)" in 1998 from the university Paris-Sud Orsay. After being assistant professor from 1994 to 2003 in Ecole Normale Supérieure de Cachan (ENSC), he is a Full Professor in University Paris Est Créteil (UPEC), France since 2003, where he is responsible for the master degree in education in sciences \& technology in the "Ecole Supérieure de l'Education et du Professorat (ESPE)". Since 2013, he is responsible for the "components \& systems for electrical energy" department (CSEE) of lab SATIE CNRS. This department covers all the fields of research in electrical power conversion: design \& integration in power electronics, reliability of power components, EMI issues, materials for electrical energy, electrical actuators design and control. His research fields include high-frequency medium-power converters, EMI issues and modelling, HF instrumentation, integration in power electronics, piezoelectric converters and low-level energy harvesting systems. He is the author or coauthor of more than 60 journal papers, 3 books and more than 150 conference papers. 